\title{
Editorial: Industrial relevance of molybdenum in China
}

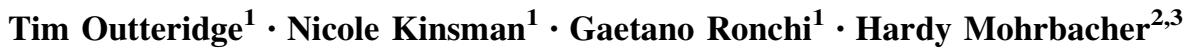

Received: 27 June 2019/Revised: 5 July 2019/Accepted: 5 July 2019/Published online: 10 September 2019

(C) The Author(s) 2019

\begin{abstract}
About $80 \%$ of all molybdenum mined in the world (not including units recovered via recycling) is used as an alloying element in iron and steel. In general, the intensity of molybdenum use in China is still lower than in more highly developed regions such as the USA and Europe. This difference is manifest in both carbon steels and stainless steels, suggesting a significant opportunity for more widespread use of molybdenum in the future as China follows its self-reliance policy, calling for more sophisticated materials. Active market development, as being pursued by the International Molybdenum Association (IMOA), is a key asset in that respect. This article summarizes some key facts on molybdenum mining, use and market development in China.
\end{abstract}

Keywords China molybdenum industry · Global molybdenum reserves - Molybdenum applications · Enduser markets · Molybdenum alloying · Market development

\section{Global molybdenum reserves}

According to the United States Geological Survey (USGS), almost half the world's reserves of molybdenum are located in Chinese territory [1]. Other significant reserves, accounting for $40 \%$ of the total, are found in North and South

Tim Outteridge

toutteridge@imoa.info

International Molybdenum Association, London, UK

Department of MTM, KU Leuven, Leuven, Belgium

3 NiobelCon bvba, Schilde, Belgium
America (see Fig. 1). In the opinion of the USGS “...resources of molybdenum are adequate to supply world needs for the foreseeable future". Figure 2 indicates the major regions of first-use, i.e., freshly mined molybdenum production. The total production volume of around $259000 \mathrm{t}$ is quite well balanced over three major mining hubs, China, South America and North America, although China is by far the largest single producing country. Figure 3 reveals that China is also the largest user of molybdenum in the world, yet, it does not dominate the international molybdenum market in terms of supply, nor demand for products, as it is largely self-sufficient. East/West trade represents only a small percentage of its output and use. Whereas imports are predominantly raw materials, exports are mainly in the form of downstream value-added products, so in this respect, the trade of molybdenum follows a familiar pattern.

\section{Molybdenum miners and products in China}

In 2018, China's use of molybdenum reached a record level of over $97000 \mathrm{t}$ [2] whilst it produced almost $92000 \mathrm{t}$ of molybdenum. Accordingly, the country was a net-importer of molybdenum. The majority (nearly $85 \%$ ) of molybdenum production in China originates from primary mines, where molybdenum is the sole mineral target, while the remainder comes as a byproduct of copper mining. The key producers Jinduicheng, China Moly, Yichun Luming and Manzhouli China Gold represent a large proportion of Chinese concentrate production. Some major producers have integrated downstream capacity to manufacture value added molybdenum products, supplying users directly. However, there is a large segment of the mining industry that produces molybdenum concentrates only, relying on independent converters and downstream manufacturers, to 


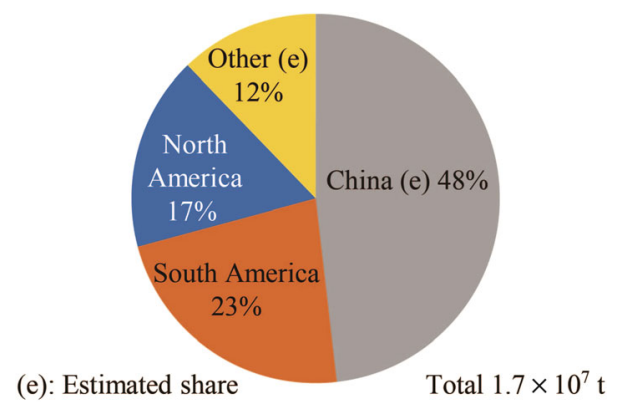

Fig. 1 Global distribution of known molybdenum reserves [1]

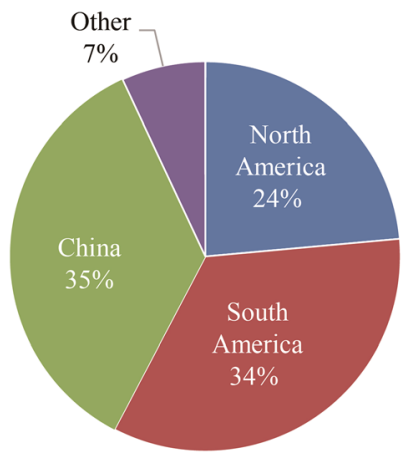

Fig. 2 Regional share of worldwide molybdenum production (basis $259000 \mathrm{t}$ ) for the year 2018, excl. scrap (Source: IMOA)

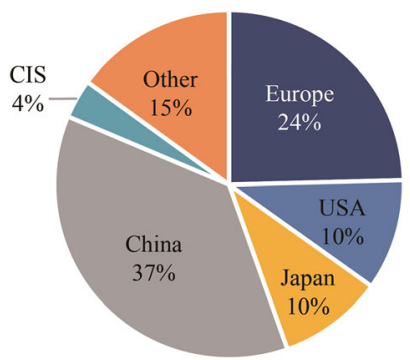

Fig. 3 Regional share of worldwide molybdenum use (264 $000 \mathrm{t}$ ) for the year 2018, excl. scrap (Source: SMR [2])

make metallurgical and chemical products, for their markets. The dramatic growth of the Chinese steel industry, which now exceeds $50 \%$ of global production as well as the limited availability of local scrap mean that primary raw

Table 1 Ferromolybdenum (FeMo) and molybdate $\left(\mathrm{MoO}_{4}{ }^{2-}\right)$ production in China from 2016 to 2018 (Sources: Comelan and International Molybdenum Association)

\begin{tabular}{llllllll}
\hline Year & \multicolumn{2}{l}{ Output/t } & & \multicolumn{3}{l}{ Share/\% } \\
\cline { 2 - 3 } & FeMo & Molybdate & Total & & FeMo & Molybdate & Total \\
\hline 2016 & 60701 & 20170 & 80871 & & 75 & 25 & 100 \\
2017 & 70469 & 20323 & 90753 & 78 & 22 & 100 \\
2018 & 74447 & 17123 & 91570 & 81 & 19 & 100 \\
\hline
\end{tabular}

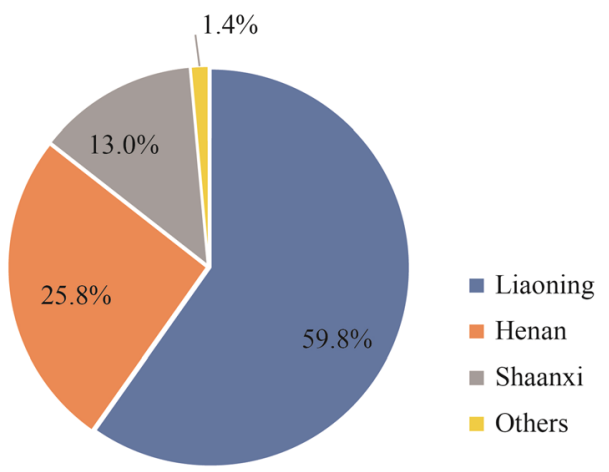

Fig. 4 Chinese FeMo production share by province in 2018 relative to a total output of $74400 \mathrm{t}$

materials such as ferromolybdenum (FeMo), continue to be in high demand. The share of FeMo has been steadily growing in the last three years and in 2018 it exceeded $80 \%$ of the total Chinese molybdenum production while the output of molybdate diminished over the same period (see Table 1).

Ferromolybdenum production in China is geographically localized in the three provinces Liaoning, Henan and Shaanxi. FeMo production in Shaanxi and Henan is highly concentrated, with Jinduicheng and China Moly being the dominant players in these provinces, whereas the production in Liaoning province is fragmented with nearly 20 producers being active. The top three companies in that province, China New Dragon, Huludao Wanfeng and Chaoyang Jinda, produce close to half of the regional FeMo output (see Fig. 4).

\section{First- and end-uses of molybdenum in China}

China uses around $30 \%$ of the world's molybdenum including that recurring via scrap recycling. The first-uses of molybdenum in China are detailed in Fig. 5 and compared to those in the rest of the world. Alloy steels and stainless steels dominate the first uses of molybdenum. In comparison with other markets, China uses a smaller share of molybdenum in super alloys, stainless steels and alloy steels, and a higher share in tool and high-speed steels, molybdenum metal, castings and chemicals.

The main end-uses and major relevant application sectors of molybdenum are identified in Fig. 6. Here, some significant differences between China and the rest of the world become apparent. In particular, a much smaller share of molybdenum is used in the oil \& gas sector. This is partially due to the fact that China is not a major oil producing country. Furthermore, the production of pipe steel, which depends highly on active pipeline construction projects, was relatively low in the period considered 


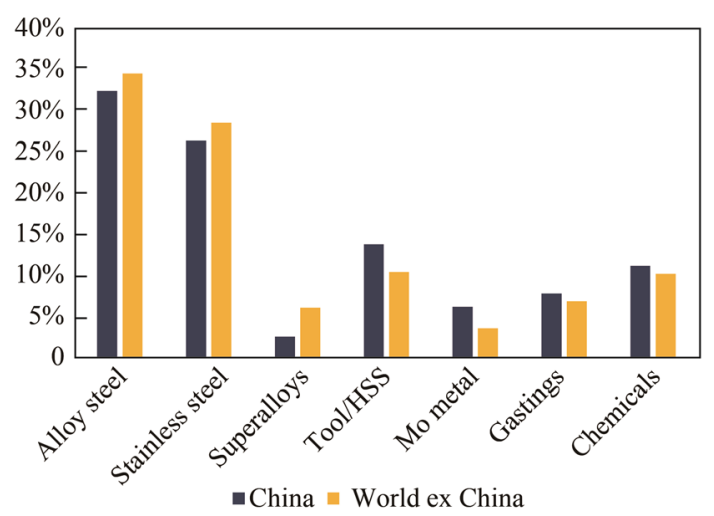

Fig. 5 First-uses of molybdenum in China and the rest of the world (excluding scrap recurrence) in the year 2017 (Source: SMR [2])

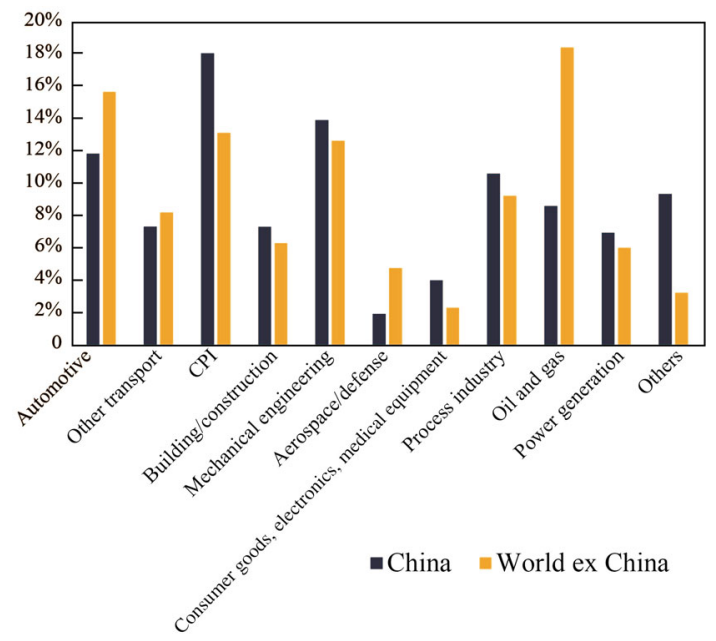

Fig. 6 End-uses of molybdenum in China and the rest of the world (including scrap recurrence) in the year 2017 (Source: SMR [2])

(2017), but consumed a large amount of molybdenum in other years. The recent West-to-East gas pipeline strings, for instance, used in the order of $10000 \mathrm{t}$ of molybdenum each for alloying the typically applied X80 grade steel $(0.2 \%-0.3 \%$ (mass fraction) $\mathrm{Mo})$ as well as in welding consumables used for pipe manufacturing and installation. Comparably smaller also, are the uses of molybdenum in the automotive and aerospace/defense sectors. Despite being the country with the largest vehicle production worldwide, less molybdenum is used in engineering steels for power train applications and also, turbochargers requiring molybdenum-containing heat-resistant alloys are less prevalent in China. The lower use of molybdenum in the aerospace/defense sector is mainly related to the fact that there is no domestic production of aircraft turbines in China, yet. On the contrary, China uses relatively more molybdenum in sectors such as chemical process industries (CPI), building and construction, mechanical engineering, consumer goods, electronics and medical equipment, non-

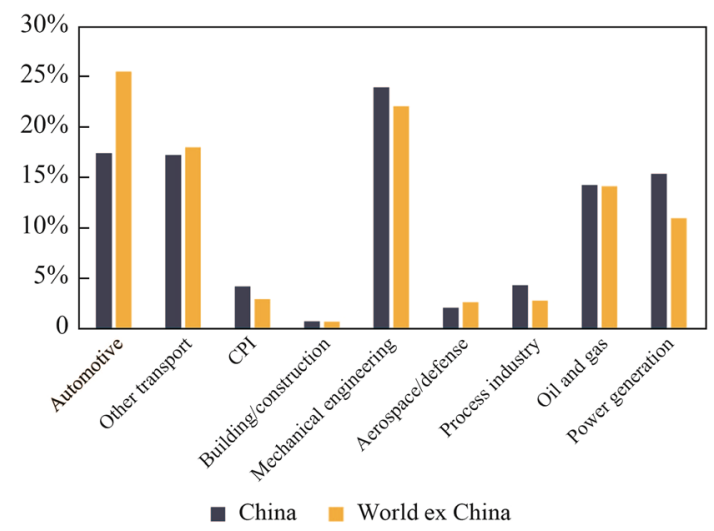

Fig. 7 End use application sectors for alloy steels in China and the world ex China (Source: SMR report [2])

chemical process industries, power generation and others. This is related to significant investments in these areas as a consequence of general economic growth as well as the specific target of producing increasingly higher-value added and internationally competitive products.

\section{Molybdenum market development activities in China}

Similar to other regions, the largest share of molybdenum use in China is found in alloyed engineering steels, followed by stainless steel [2]. However, even though China nowadays produces $52 \%$ of all carbon steel and $53 \%$ of all stainless steel globally, the specific use of molybdenum as an alloying element is still smaller than in other markets. In the carbon steel sector, the specific use of molybdenum (including the units recovered form scrap) currently reaches approximately $55 \mathrm{~g} / \mathrm{t}$ compared to the average of $133 \mathrm{~g} / \mathrm{t}$ in other major steel producing countries [3]. The corresponding figures for stainless steel are $1.1 \mathrm{~kg} / \mathrm{t}$ in China versus $2.9 \mathrm{~kg} / \mathrm{t}$ in other major stainless steel producing countries. Consequently, there is a significant potential to increase the use of molybdenum in the Chinese steel industry by adopting alloy design solutions from other regions and by deploying local product development activities. The comparison of end uses for alloy steels shown in Fig. 7 suggests that steel development for automotive applications should be a priority for molybdenum market development since the gap between China and the highly developed markets is the largest in this area. Furthermore, the automotive industry is highly globalized and requires local supplies of alloys in major production countries according to the material standards established at the home base. Other sectors relevant to market development are the machine building industry, and the production of heavy-duty transport equipment. 
Chinese steel companies have made major investments in steel production facilities over the last two decades. Consequently, they have at their disposal some of the most modern and capable equipments, principally allowing the processing of leading-edge steel products. In many such products molybdenum can be a decisive alloying element, where the benefits of its use to improve steel properties go far beyond just increasing strength and hardness. The lesser-known metallurgical benefits of molybdenum alloying often make it the ideal alloying element for today's advanced manufacturing techniques and high-end applications. In that respect, it is necessary to demonstrate and communicate the full metallurgical potential of molybdenum alloying. Additionally, it is of key importance to explain that the obtained benefits of molybdenum containing steels outweigh the additional alloy cost [4].

IMOA's market development program is fully dedicated to communicating the known benefits of molybdenum alloying, demonstrating cost-benefit analyses and discovering new advantageous metallurgical effects. The practical implementation of that program consists of three major activities being knowledge dissemination, alloy implementation and knowledge generation. Knowledge dissemination relies on regular visits to steelmakers and end users often combined with in-house seminars. On occasions, symposia have been organized bringing a larger number of experts together, typically representing all relevant players in the area of interest. In selected cases of significant urgency, alloy implementation is assisted by direct consulting and support actions. Due to the prominent size of China's metallurgical industry, academic research activities in alloy related topics are higher than elsewhere in the world. IMOA interacts with Chinese research facilities via academic lectures or by funding $R \& D$ projects. In that way, existing knowledge is passed on to the next generation of metallurgists and new scientific understanding is created. For all IMOA market development activities, the topical focus has always been closely aligned with China's economic and industrial development priorities. In the different phases of the IMOA market development program, the focus was initially on steel for infrastructural applications including high strength pipeline steel. Later, the development of ultra-high strength steel for light-weighting of passenger and commercial vehicles became a dominant area of activities. Currently, two important initiatives are underway. A knowledge generating project investigating the effects of molybdenum alloying in cast iron components has been established at Shanghai University. An alloy implementation support activity aims to develop new highperformance gear steel with leading Chinese producers of special steels as well as major domestic manufacturers of automotive and large machinery gears.
Open Access This article is distributed under the terms of the Creative Commons Attribution 4.0 International License (http://crea tivecommons.org/licenses/by/4.0/), which permits unrestricted use, distribution, and reproduction in any medium, provided you give appropriate credit to the original author(s) and the source, provide a link to the Creative Commons license, and indicate if changes were made.

\section{References}

1. United States Geological Survey (USGS)—National Minerals Information Center (2019). Accessed 09 May 2019

2. Moll M (2018) Molybdenum end use analysis 2018, Steel \& Metals Market Research GmbH (SMR), Reutte, Austria

3. IMOA estimate based on data from Worldsteel, ISSF and SMR

4. Mohrbacher H (2013) Reverse metallurgical engineering towards sustainable manufacturing of vehicles using $\mathrm{Nb}$ and Mo alloyed high performance steels. Adv Manuf 1:28-41

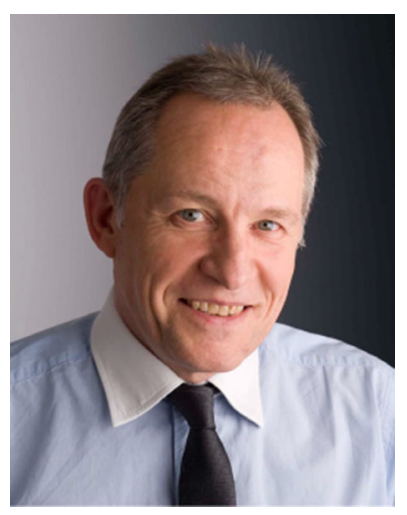

Tim Outteridge is the Secretary-General of the International Molybdenum Association (IMOA). He graduated in 1978 with a degree in Metallurgy from the University of Sheffield and started his career in the molybdenum industry at Noranda Sales Corporation in London. From 1990 he held responsibility for the global molybdenum business at Noranda and later took on the same role in Rio Tinto, at Kennecott Utah Copper. He joined IMOA in 2008.

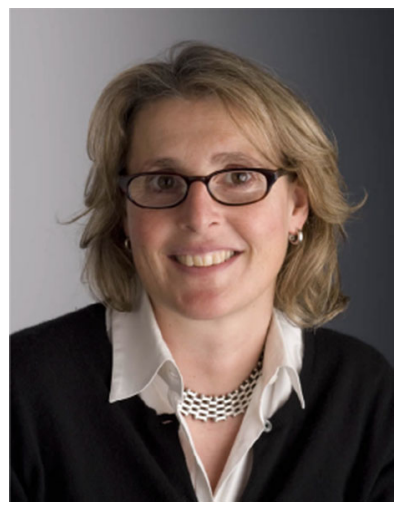

Nicole Kinsman is IMOA's Technical Director. She is a mechanical engineer with a PhD in metallurgy from the Swiss Federal Institute of Technology and an MBA from Carnegie Mellon University. Before joining IMOA she was a Market Development Manager at TMR, a stainless steel consulting firm in Pittsburgh, PA. She has specialized in stainless steel technical market development for over twenty years. 


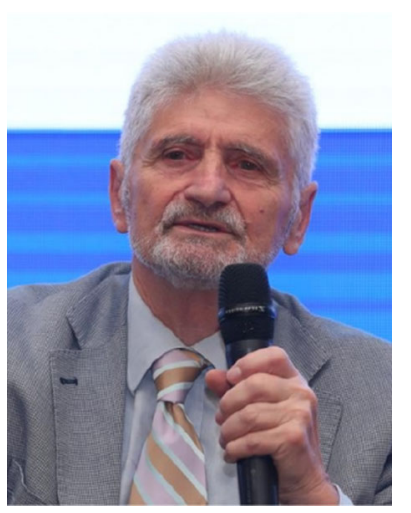

Gaetano Ronchi is IMOA's Senior Consultant in Asia since 2013. He has a $\mathrm{PhD}$ in electromechanical engineering from Politecnico Milano; is a certified as a welding engineer by the Italian Welding Institute and has an MBA from Stockholm School of Economics. He has over 45 years' experience in metals welding with a particular focus on stainless steel and advanced corrosion resistant grades. During his career, Gaetano has held many senior roles including Managing Director of a Sandvik Steel subsidiary, CEO and Sales and Marketing VP for Acciai Speciali Terni and Managing Director of Avesta (now Outokumpu).

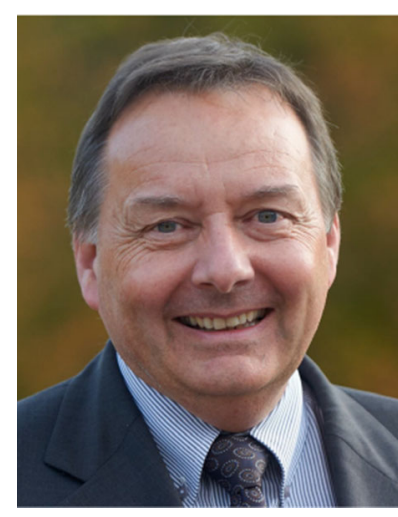

Hardy Mohrbacher specializes in materials and mechanical engineering including steel alloy design and processing, sheet metal forming and welding, automotive body design, non-destructive testing and materials characterization, plus the tribology of hard materials. He has held senior roles within, among others, Fraunhofer Institute for Nondestructive Testing (IZFP), Sidmar (ArcelorMittal Ghent) and ThyssenKrupp (TKTB). $\mathrm{He}$ is an Associate Professor at KU Leuven in Belgium and an Adjunct Professor at China's Shanghai University. 